\title{
Correlações simples entre as medidas de ultra-som e a composição da
} carcaça de bovinos jovens

\section{Liliane Suguisawa ${ }^{1}$, Wilson Roberto Soares Mattos ${ }^{2}$, Henrique Nunes de Oliveira ${ }^{3}$, Antônio Carlos Silveira ${ }^{3}$, Mário de Beni Arrigoni ${ }^{3}$, André Alves de Souza ${ }^{1}$}

\author{
1 Pós-graduandos em Nutrição e Produção Animal - FMVZ/UNESP/Botucatu-SP. \\ ${ }^{2}$ Depto. Produção Animal - USP/ESALQ, C.P. 09, CEP: 13418-220 - Piracicaba/SP. \\ ${ }^{3}$ Depto. Melhoramento Genético e Nutrição Animal - FMVZ/UNESP, C.P. 560, CEP: 18618-000 - Botucatu/SP.
}

RESUMO - Neste estudo avaliaram-se as correlações entre as medidas ultra-sonográficas e as características de carcaça de 115 bovinos jovens (Nelore, 1/2 Angus Nelore, 1/2 Simental Nelore e Canchim), com peso inicial médio de $329 \mathrm{~kg}$ e dois tamanhos à maturidade (pequeno e grande), em um sistema de produção do novilho superprecoce. Aos 120 dias de confinamento, foram realizadas a pesagem e medida da área de olho-de-lombo (AOL) e da gordura subcutânea (ECG), via ultra-sonografia. Após o abate, foram coletadas as medidas de AOL e ECG na carcaça e os pesos de traseiro, dianteiro e cortes cárneos comerciais, determinando-se também a composição corporal dos animais. Foram calculados os rendimentos de carcaça, cortes cárneos, traseiro, da AOL ultrasom por $100 \mathrm{~kg}$ de PV e da AOL carcaça por $100 \mathrm{~kg}$ de peso de carcaça. Dados da composição da carcaça indicaram alta deposição muscular nos animais $1 / 2$ Simental Nelore e Canchim e expressiva deposição de tecido adiposo nos animais Nelore. No entanto, os animais $1 / 2$ Angus Nelore mostraram-se mais apropriados para confinamento no sistema de produção do superprecoce, pois equilibraram musculosidade e gordura de acabamento. Os resultados demonstraram que a AOL tem relação com a musculosidade da carcaça e que, à medida que há seleção para o incremento desta característica, ocorre diminuição da ECG, como resultado da correlação negativa da ECG com a porcentagem de traseiro e AOL. Não foi observada diferença na composição entre os dois grupos de tamanho à maturidade, provavelmente em razão da pequena variação entre eles. Como as correlações envolvendo a AOL e a ECG por ultra-som e as mesmas medidas na carcaça apresentam resultados similares, validou-se a utilização da técnica da ultra-sonografia como alternativa para predição das características da carcaça de bovinos.

Palavras-chave: composição, cortes cárneos, gordura, musculosidade, rendimento

\section{Correlations between ultrasound measurements and carcass composition of young bulls}

\begin{abstract}
The objective of this study was to evaluate correlations between ultrasonography measurements and carcass traits of 115 steers (Nellore, $1 / 2$ Angus-Nellore, 1/2 Simmental-Nellore, and Canchim) averaging $329 \mathrm{~kg}$ of initial body weight and two different finishing frame sizes (small and large). After 120 days in a feedlot, body weight, rib eye area (RA), and fat thickness (FT) were measured by ultrasound. Following slaughter, carcass RA and FT measurements and weights of hindquarter, forequarter, and commercial cuts were all taken; body composition was also determined. Yields of carcass, retail cuts, and hindquarter as well as ratios of ultrasound RA per $100 \mathrm{~kg}$ of body weight and ultrasound RA per $100 \mathrm{~kg}$ of carcass weight were calculated. Data showed higher muscle deposition in $1 / 2$ Simental-Nellore and Canchim and greater fat deposition in Nellore while $1 / 2$ Angus-Nellore steers combined both characteristics. According to the results, RA was a good indicator of the proportion of muscle present in the carcass and selection for increasing carcass RA may decrease FT because of the negative correlation between FT and hindquarter percentage and RA. Frame size did not affect carcass composition possibly due to the small variation between both groups. Because correlations of measured and ultrasound RA and FT with carcass components yielded similar results, it was possible to validate ultrasound measurements to predict carcass composition of young bulls.
\end{abstract}

Key Words: carcass yield, composition, fat, muscle, retail cuts

\section{Introdução}

Atualmente, a produção de carcaças de peso adequado e com quantidade mínima de gordura subcutânea, de forma a garantir a qualidade da carne durante o processo de resfriamento, é um dos principais interesses dos produtores de bovinos. Joandet \& Cartwright (1975) já indicavam que as perdas econômicas provenientes do abate de animais fora do peso ideal poderiam equivaler a quedas de aproximadamente $10 \%$ na taxa de fertilidade.

O conhecimento da condição corporal (deposição de gordura subcutânea) e do desenvolvimento muscular dos 
animais, ou da composição corporal, na forma de porcentagem dos constituintes da carcaça (músculo, osso e gordura), é muito importante para avaliação de grupos genéticos e tratamentos nutricionais que envolvem o crescimento animal e a determinação de exigências nutricionais (Luchiari Filho, 2000; Cruz et al., 2001). No entanto, é bastante trabalhosa e de custo elevado, o que torna sua execução por métodos diretos inviável, mesmo em rotinas experimentais (Lanna, 1988; Galvão et al., 1991; Jorge et al., 1997).

A avaliação de carcaça por predições in vivo pode garantir a economicidade do processo produtivo, pois possibilita a determinação do grau de terminação e de desenvolvimento muscular dos animais. Porém, estas informações ainda são normalmente determinadas por inspeção visual ou por meio de palpação, estando sujeita a erros de avaliação (Frost et al., 1997). Diversas metodologias têm sido desenvolvidas visando à predição da composição corporal dos animais com base na avaliação dos animais vivos, possibilitando a identificação de alterações na composição da carcaça decorrentes de fatores como raça, sexo e manejo nutricional, entre outros (Bailey et al., 1986; Perón et al., 1995; Silva et al., 2001).

A técnica de ultra-sonografia é uma alternativa para predição in vivo das características da carcaça, principalmente no sistema de produção do novilho superprecoce, no qual os animais são abatidos com 12 a 15 meses de idade, quando se exige o máximo de sua eficiência de crescimento (Silveira, 1999). O monitoramento de características como área de olhode-lombo(AOL) e espessura da camada de gordura subcutânea (ECG), além de auxiliar na escolha dos animais para o abate, fornece informações úteis para incorporação em modelos de crescimento e seleção animal (Arnold etal., 1991; Bullock et al., 1991; Hamlin et al., 1995; Bergen et al., 1996).

Neste trabalho, foram correlacionadas as medidas \}obtidas nos animais vivos, pela técnica de ultra-sonografia, e as características de carcaça de bovinos jovens, para verificar o potencial do ultra-som na predição da composição da carcaça de bovinos de corte submetidos ao sistema de produção do novilho superprecoce, objetivando o fornecimento de informações para a adequação de sistemas de manejo e alimentação nos biótipos avaliados.

Embora a exatidão da predição da AOL e ECG por ultrasonografia seja fundamental para o treinamento de técnicos especializados e para fins de pesquisa científica (Faulkner et al., 1990; May et al., 2000), para os produtores de bovinos, é mais importante a predição das características de produção de carne que possam ser incorporadas, de alguma maneira, em programas de seleção e que possibilitem o aumento do retorno econômico da atividade (Bergen et al., 1997). Nesse contexto, objetivou-se com este estudo avaliar a aplicabilidade da técnica de ultra-sonografia para predição das variáveis que interferem na composição de carcaça de bovinos jovens.

\section{Material e Métodos}

O ensaio experimental foi realizado no setor de confinamento de bovinos de corte da Fazenda Lageado, pertencente à Faculdade de Medicina Veterinária e Zootecnia da UNESP, em Botucatu/SP, no período de 19 de outubro de 2000 a 13 de março de 2001 . Foram utilizados 115 bezerros machos não-castrados, com peso médio inicial de $329 \mathrm{~kg}$, de dois tamanhos à maturidade, dos seguintes grupos genéticos: Nelore, $1 / 2$ Angus Nelore, $1 / 2$ Simental Nelore e Canchim. Desse modo, havia 30 animais de cada grupo genético ( 15 de tamanho pequeno à maturidade e 15 grandes), com exceção dos animais Nelore (um total de 25), divididos em 15 de tamanho pequeno à maturidade e 10 grandes. Os animais foram divididos quanto ao tamanho à maturidade (TM), segundo metodologia de Dhuiyvetter (1995), empregando a seguinte equação:

$\mathrm{TM}=-11,45+(0,04878 \mathrm{x}$ altura da anca $)-(0,0289 \mathrm{x}$ idade $)+(0,00001947 \mathrm{x} \text { idade })^{2}+(0,0000334 \mathrm{x}$ altura da anca $)$ $\mathrm{x}$ (idade)

Utilizou-se confinamento de alvenaria, coberto, equipado com um bebedouro automático por baia e com capacidade física para 180 animais, dispostos em 26 baias. Em razão da diferente procedência, as datas de entrada do animais no confinamento também foram distintas: $1 / 2$ Simental Nelore $=19 / 10 / 2000 ; 1 / 2$ Angus Nelore e Canchim $=25 / 10 /$ $2000 ;$ Nelore $=27 / 10 / 2000$. No início do experimento, todos os animais foram identificados individualmente, tratados contra endo e ectoparasitas (Ivermectina) e distribuídos ao acaso nos currais de confinamento em grupos de cinco, de acordo com a raça e o tamanho, sendo alimentados com dietas, isoenergéticas e isoprotéicas, formuladas de acordo com as normas do NRC (1996), nível II, para conter 16\% de $\mathrm{PB}, 74 \%$ de NDT e $1,14 \mathrm{Mcal} / \mathrm{kg}$ de energia líquida para ganho de peso médio diário de $1,35 \mathrm{~kg}$.

Os animais passaram por um período de adaptação (15 dias) no qual foram alimentados com dieta contendo relação volumoso:concentrado 40:60, gradativamente aumentada para evitar possível estresse nutricional nos animais. Os alimentos foram fornecidos duas vezes ao dia (refeições iguais), às 8 e 15h, efetuando, semanalmente, o controle do consumo por baia, por meio do cálculo da quantidade de alimento ofertado e das sobras. Após a adaptação, a relação volumoso:concentrado foi de 21:79\% na matéria seca (Tabela 1). 
As pesagens e medidas ultra-sonográficas foram realizadas antes do abate, segundo metodologia descrita por Herring et al. (1994), após jejum de 12 horas. Para realização da ultra-sonografia, efetuou-se a limpeza do local, entre a $12 \underline{a}$ e $13 \underline{a}$ costelas do lado esquerdo do animal, e, em seguida, colocou-se óleo vegetal no dorso, para perfeito acoplamento do transdutor com o corpo do animal. O transdutor foi disposto de maneira perpendicular ao comprimento do contra-filé (músculo Longissimus dorsi), entre a $12^{\mathrm{a}}$ e $13^{\mathrm{a}}$ costelas, onde foi tomada a imagem ultrasonográfica. Durante a leitura da imagem, circundou-se a AOL que aparece no monitor do aparelho, obtendo-se instantaneamente sua medida e da ECG, no terço proximal da imagem do músculo. O equipamento de ultra-sonografia utilizado foi o PIEMEDICAL Scanner 200 VET, com transdutor de 3,5 MHz de $18 \mathrm{~cm}$ e uma guia acústica.

Após confinamento dos mestiços Simental, 1/2 Angus Nelore e Canchim e dos animais Nelore durante 111, 119 e 139 dias, respectivamente, todos os animais foram abatidos no frigorífico FRIGOL de Lençóis Paulista/SP nas seguintes datas: $07 / 02 / 2001=1 / 2$ Simental Nelore; $21 / 02 / 2001=$ $1 / 2$ Angus Nelore e Canchim; 15/03/2001= Nelore. O critério de abate, peso final mínimo de $480 \mathrm{~kg}$ e ECG mínima de $3 \mathrm{~mm}$ monitorada por ultra-sonografia, foi aplicado a todos os grupos genéticos. Após o abate, as carcaças foram identificadas, pesadas e resfriadas por 24 horas. Em seguida, coletaramse 65 amostras da seção entre a $12^{\mathrm{a}}$ e $13^{\mathrm{a}}$ - costelas provenientes de 18 animais 1/2 Angus Nelore, 17 Canchim, 12 1 1/2 Simental Nelore e 18 animais Nelore, para obtenção das medidas de AOL e ECG na carcaça, realizadas duas semanas após o abate dos animais no Laboratório de Carnes da UNESP/Botucatu - SP, onde as peças permaneceram armazenadas sob resfriamento a $-5^{\circ} \mathrm{C}$. A AOL foi mensurada utilizando-se régua de quadrantes de pontos (Luchiari

Tabela 1 - Composição da dieta fornecida durante o confinamento Table 1 - Diet composition fed to feedlot animals

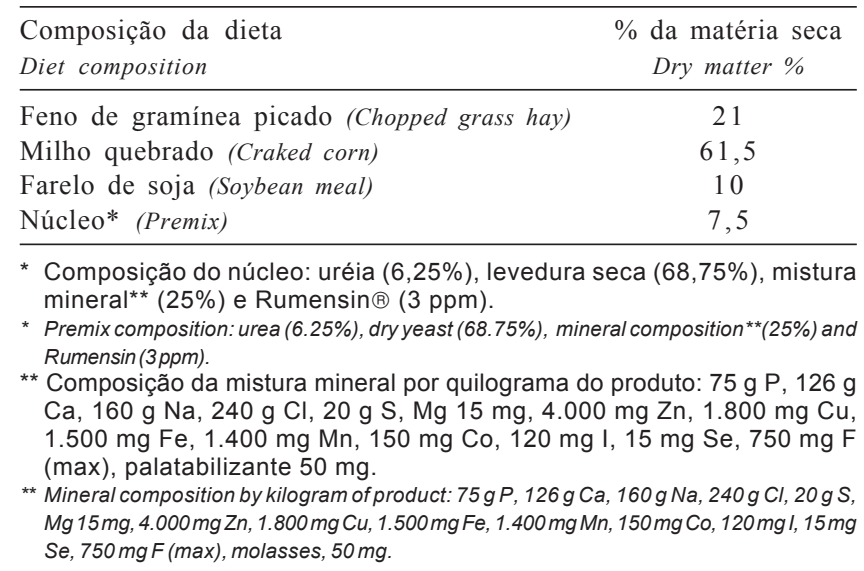

Filho, 2000) eaECG, por meio de um paquímetro. Coletaram-se também, após o resfriamento, 71 amostras da secção da 9 a a 11 a costelas (secção HH) de 18 animais $1 / 2$ Angus Nelore, 17 Canchim, 18 1/2 Simental Nelore e 18 Nelore, para estimação da composição corporal, segundo metodologia descrita por Hankins \& Howe (1946), que envolve a separação física dos três principais componentes desta secção (tecidos muscular, adiposo e ósseo) e o cálculo de sua participação percentual na amostra, utilizados para estimativa da composição corporal de toda a carcaça, segundo as equações:

$$
\begin{gathered}
\mathrm{TM}=16,08+0,80 \mathrm{X} \\
\mathrm{TA}=3,54+0,80 \mathrm{X} \\
\mathrm{TO}=5,52+0,57 \mathrm{X}
\end{gathered}
$$

em que TM é a quantidade percentual de tecido muscular; TA, a quantidade percentual de tecido adiposo; TO, a quantidade percentual de tecido ósseo; e X, a porcentagem do respectivo componente na secção $\mathrm{HH}$.

Os pesos do traseiro, do dianteiro e dos cortes cárneos comerciais foram determinados nas mesmas meia-carcaças utilizadas para obtenção das amostras para a secção HH. Para o peso do traseiro, foi incluída também a ponta-deagulha (quarto traseiro ou traseiro comum). Os músculos contra-filé e o filé mignon não foram computados no peso dos cortes cárneos comerciais do traseiro, pois a retirada da secção HH incluía parte deles. A partir dos pesos do traseiro, do dianteiro e dos cortes cárneos comerciais, foram calculados os rendimentos de carcaça (peso da carcaça total/peso vivo), de cortes cárneos (cortes cárneos/peso da carcaça quente) e de traseiro (peso do traseiro/peso da carcaça quente), a medida de AOL por $100 \mathrm{~kg}$ de peso vivo (AOLUPKG) e a medida da AOL por $100 \mathrm{~kg}$ de carcaça (AOLPCAR).

O delineamento experimental para as medições ultrasonográficas e das características de desempenho tomadas ao longo do confinamento foi em parcelas subdivididas, em arranjo fatorial $4 \times 2$ (quatro grupos genéticos $\mathrm{x}$ dois tamanhos à maturidade), em que as subparcelas consistiram nas medidas repetidas em cada animal dentro de raça e tamanho. Para as demais características, adotou-se o delineamento inteiramente casualisado e, para aquelas em que houve efeito de interação, foi realizado o desdobramento dos graus de liberdade, aplicando-se o teste de StudentNeumam-Kleus (SNK) para comparação de médias. Em razão da pequena importância do tamanho à maturidade sobre estas características, o efeito de interação foi desconsiderado nas análises finais. Todas as análises foram realizadas utilizando-se o procedimento GLM do sistema de análises estatísticas SAS (SAS, 1987). 


\section{Resultados e Discussão}

Não houve efeito significativo da idade sobre as características e a composição da carcaça dos animais, sugerindo que a correção da idade não proporcionou melhorias na interpretação dos resultados, provavelmente em razão da uniformidade dos grupos genéticos estudados. Também não houve efeito de interação entre as características avaliadas.

$\mathrm{Na}$ Tabela 2 constam as médias de alguns dos principais componentes da carcaça, de acordo com o grupo genético. Foram observados efeitos significativos de grupo genético sobre a maioria das variáveis $(\mathrm{P}<0,05)$, à exceção do rendimento de carcaça, da porcentagem de ossos, da quantidade de gordura e do peso dos cortes cárneos comerciais. A relação entre medidas de $\mathrm{AOL}$ e peso vivo dos animais ou da carcaça é realizada para reduzir a influência do peso vivo e do grau de musculosidade dos diferentes grupos genéticos, facilitando sua adequada comparação (Bergen et al., 1997). Neste estudo, os animais Canchim apresentaram AOLUPKG maior que os $1 / 2$ Simental Nelore. Os animais Nelore e os $1 / 2$ Angus Nelore apresentaram valores intermediários, não diferindo estatisticamente dos demais grupos genéticos estudados $(\mathrm{P}>0,05)$. Bergen et al. (1997) registraram os maiores valores de AOLUPKG em animais Charolês $\left(16,2 \mathrm{~cm}^{2} / 100 \mathrm{~kg}\right)$, porém, diferentemente deste estudo, as raças britânicas Angus, Hereford e Shorthorn apresentaram os menores valores $\left(14,8\right.$ e $14,9 \mathrm{~cm}^{2} / 100 \mathrm{~kg}$ ), enquanto a raça Simental, valores intermediários para esta medida $\left(15,5 \mathrm{~cm}^{2} / 100 \mathrm{~kg}\right)$. Foram observadas diferenças significativas entre os grupos genéticos, tanto para AOLUPKG como para o rendimento de cortes cárneos $(\mathrm{P}<0,05)$. Animais da raça Canchim foram superiores aos $1 / 2$ Simental Nelore e semelhantes ao Nelore, evidenciando superioridade da raça Canchim (Tabela 2).

Neste trabalho, todos os grupos genéticos alcançaram o valor indicado por Luchiari Filho (2000), de $29 \mathrm{~cm}^{2} / 100 \mathrm{~kg}$ de carcaça, observando-se que os $1 / 2$ Simental Nelore $(33,75$ $\mathrm{cm}^{2} / 100 \mathrm{~kg}$ carcaça $)$, Canchim $\left(33,32 \mathrm{~cm}^{2} / 100 \mathrm{~kg}\right.$ carcaça $) \mathrm{e}$ $1 / 2$ Angus Nelore $\left(31,55 \mathrm{~cm}^{2} / 100 \mathrm{~kg}\right.$ carcaça) alcançaram valores significativamente superiores $(\mathrm{P}<0,05)$ aos dos animais Nelore $\left(29,12 \mathrm{~cm}^{2} / 100 \mathrm{~kg}\right.$ carcaça). Apesar do acréscimo da AOLPCAR em relação aos animais Nelore, as diferenças significativas no rendimento de cortes cárneos comerciais não foram adequadamente explicadas pelas medidas de AOLPCAR, o que corrobora os dados reportados por Cruz et al. (2001), que observaram dados significativamente diferentes de AOLPCAR - 31,90 $\mathrm{cm}^{2} / 100 \mathrm{~kg}$ carcaça para animais de $400 \mathrm{~kg}, 31,53 \mathrm{~cm}^{2} / 100 \mathrm{~kg}$ carcaça para animais com $440 \mathrm{~kg}$ e $30,71 \mathrm{~cm}^{2} / 100 \mathrm{~kg}$ carcaça para animais de $480 \mathrm{~kg}$ de PVA - e não constataram diferença significativa quanto ao rendimento de cortes cárneos.

Quanto aos componentes da carcaça, existe óbvia relação negativa entre as porcentagens de músculo e de gordura entre os grupos genéticos. Os animais $1 / 2$ Simental Nelore apresentaram a maior porcentagem de músculo na carcaça, seguidos dos Canchim e $1 / 2$ Angus Nelore $(\mathrm{P}<0,05)$.

Tabela 2 - Composição corporal e características de carcaça nos grupos genéticos Table 2 - Body composition and carcass traits in genetic groups

\begin{tabular}{|c|c|c|c|c|c|c|}
\hline \multirow[b]{2}{*}{$\begin{array}{l}\text { Variável } \\
\text { Trait }\end{array}$} & \multirow[b]{2}{*}{$\mathrm{n}$} & \multirow[b]{2}{*}{$\mathrm{CV}$} & \multicolumn{4}{|c|}{$\begin{array}{l}\text { Grupo genético } \\
\text { Genetic group }\end{array}$} \\
\hline & & & $1 / 2$ Angus Nelore & Canchim & $1 / 2$ Simental Nelore & Nelore \\
\hline AOLUPKG $\left(\mathrm{cm}^{2} / 100 \mathrm{~kg}\right)^{*}\left(R A U P K G, \mathrm{~cm}^{2} / 100 \mathrm{~kg}\right)$ & 111 & 9,71 & $16,40^{\mathrm{AB}}$ & $16,74^{\mathrm{A}}$ & 15,45 B & $16,20 \mathrm{AB}$ \\
\hline AOLPCAR $\left(\mathrm{cm}^{2} / 100 \mathrm{~kg}\right)^{* *}\left(R A C P C A R, \mathrm{~cm}^{2} / 100 \mathrm{~kg}\right)$ & 60 & 10,8 & $31,55^{\mathrm{A}}$ & $33,32^{\mathrm{A}}$ & $33,75^{\mathrm{A}}$ & $29,12^{\mathrm{B}}$ \\
\hline Tecido muscular (kg) (Muscle tissue, $\mathrm{kg}$ ) & 71 & 11,6 & $141,74^{\mathrm{B}}$ & $141,15^{\mathrm{B}}$ & $159,11^{\mathrm{A}}$ & $134,41^{\mathrm{B}}$ \\
\hline Músculo (\%) (Muscle, \%) & 71 & 6,07 & $57,45^{\mathrm{BC}}$ & $58,91^{\mathrm{B}}$ & $61,08^{\mathrm{A}}$ & $55,95^{\mathrm{C}}$ \\
\hline Gordura $(\%)($ Fat, \%) & 71 & 12,5 & $28,28^{\mathrm{A}}$ & $26,70^{\mathrm{A}}$ & $24,43^{\mathrm{B}}$ & $29,04^{\mathrm{A}}$ \\
\hline Ossos (\%) (Bone, \%) & 71 & 5,43 & $15,42^{\mathrm{A}}$ & $15,50^{\mathrm{A}}$ & $15,57^{\mathrm{A}}$ & $15,95^{\mathrm{A}}$ \\
\hline Cortes cárneos $(\mathrm{kg})$ (Retail cut weight, $\mathrm{kg}$ ) & 71 & 7,57 & $59,16^{\mathrm{A}}$ & $59,44^{\mathrm{A}}$ & $61,40^{\mathrm{A}}$ & $58,18^{\mathrm{A}}$ \\
\hline Peso do traseiro $(\mathrm{kg})$ (Hindquarter weight, $\mathrm{kg}$ ) & 71 & 7,43 & $151,62^{\mathrm{AB}}$ & $146,22^{B}$ & $154,66^{\mathrm{A}}$ & $143,76^{\mathrm{B}}$ \\
\hline Peso do dianteiro $(\mathrm{kg})$ (Forequarter weight, $\mathrm{kg}$ ) & 71 & 9,64 & $101,52^{\mathrm{AB}}$ & $97,34^{\mathrm{B}}$ & $107,74^{\mathrm{A}}$ & $101,94^{\mathrm{AB}}$ \\
\hline
\end{tabular}

$A, B, C$ Médias seguidas de letras iguais na mesma linha não apresentam diferenças significativas $(P>0,05)$.

$A, B, C \quad$ Means followed by the same letters in a row do not differ $(P>0.05)$.

* AOLUPKG - AOL por ultra-som $\left(\mathrm{cm}^{2}\right)$ por $100 \mathrm{~kg}$ de peso vivo.

* RAUPKG - RA ultrasound $\left(\mathrm{cm}^{2}\right)$ per $100 \mathrm{~kg}$ of body weight.

** AOLPCAR - AOL da carcaça $\left(\mathrm{cm}^{2}\right)$ por $100 \mathrm{~kg}$ de carcaça

** RAPCAR - RA carcass $\left(\mathrm{cm}^{2}\right)$ per $100 \mathrm{~kg}$ of carcass weight. 
Esse resultado era esperado para os $1 / 2$ Simental Nelore e Canchim, por se tratar de animais com grau de sangue da Europa Continental, com maior potencial de crescimento, porém, não para a raça Angus, geralmente reconhecida como uma raça de menor tamanho corporal e com potencial para acrescentar ao $1 / 2$ Angus Nelore o acúmulo de gordura mais precocemente. Os animais Nelore, Canchim e os $1 / 2$ Angus Nelore apresentaram maior porcentagem de gordura na carcaça $(P<0,05)$. Essa tendência da raça Nelore de apresentar alta porcentagem de gordura da carcaça, estimada pela mesma metodologia proposta por Hankins \& Howe (1946), já havia sido observada em outros trabalhos (Galvão et al., 1991; Jorge et al., 1997). Como observado por Jorge et al. (1997), houve pouca variação entre os grupamentos genéticos quanto à porcentagem de ossos na carcaça.

Como os cortes básicos das carcaças brasileiras são o dianteiro com cinco costelas, a ponta-de-agulha e o traseiro, constituído dos cortes cárneos mais valorizados, deve-se buscar maior rendimento de traseiro. Neste estudo, não houve efeito do grupo genético sobre a quantidade dos cortes cárneos, mas houve diferenças significativas quanto ao peso do traseiro $(\mathrm{P}<0,05)$, de modo que os animais $1 / 2$ Simental Nelore apresentaram os maiores valores, os Canchim e Nelore, os menores valores e os $1 / 2$ Angus Nelore, valores intermediários, não diferindo dos demais grupos genéticos. Apesar disso, Galvão et al. (1991) não encontraram diferenças significativas para peso do traseiro entre os diversos grupos genéticos estudados. Também houve diferenças significativas para peso de dianteiro entre os grupos genéticos $(\mathrm{P}<0,05)$, observando-se que os pesos de dianteiro dos novilhos $1 / 2$ Simental Nelore foram maiores que dos Canchim.

O peso da carcaça quente foi superior nos animais $1 / 2$ Simental Nelore $(P<0,05)$, provavelmente em razão do peso vivo final destes animais, uma vez que os $1 / 2$ Simental Nelore também apresentaram as maiores quantidades de dianteiro e traseiro $(\mathrm{P}<0,05)$. Constataram-se diferenças significativas no rendimento de traseiro entre os grupos genéticos, de modo que as médias dos $1 / 2$ Simental Nelore e dos animais Nelore foram significativamente $(\mathrm{P}<0,05)$ inferiores às dos demais grupos genéticos estudados.

Embora não tenham sido encontradas diferenças significativas quanto à quantidade, houve diferenças significativas quanto ao rendimento de cortes cárneos, observando-se que os animais Canchim apresentaram o maior valor, os Nelore, valor intermediário, e os $1 / 2$ Angus Nelore e $1 / 2$ Simental Nelore, valores menores. Portanto, como no estudo de Cruz et al. (2001), o maior peso de carcaça quente, no caso dos $1 \frac{1}{2}$ Simental Nelore, não implicou necessariamente aumento no rendimento de cortes cárneos da carcaça.
Constam na Tabela 3 as correlações estatisticamente significativas $(\mathrm{P}<0,05)$, corrigidas para efeito de grupos genéticos, das características morfométricas (medidas por ultra-sonografia ou após o abate) com os componentes da carcaça. Neste trabalho, foram encontradas correlações positivas da AOL por ultra-sonografia (AOL ultra-som) e da quantidade e porcentagem de músculo da carcaça, conforme demonstrado por Bailey et al. (1986), com a quantidade de cortes cárneos e correlação negativa com a porcentagem estimada de tecido adiposo da carcaça. Entretanto, não foi detectada correlação significativa da AOL ultra-som com a quantidade de tecido adiposo, como demonstrado por Bullock et al. (1991). Também houve correlação negativa com a porcentagem de ossos e positiva com a quantidade de tecido ósseo, corroborando o estudo de Bailey et al. (1986).

Verificaram-se correlação positiva da AOL carcaça com a quantidade de cortes cárneos e a porcentagem e quantidade de músculo e correlação negativa com a porcentagem dos tecidos adiposo e ósseo. Assim como nos trabalhos de Faulkner et al. (1990) e Peron et al. (1995), também foi observada correlação positiva da AOL da carcaça com a quantidade de ossos. Galvão et al. (1991), Peron et al. (1995) e Jorge et al. (1997), ao contrário do observado neste estudo e por Faulkner et al. (1990), demonstraram que a AOL carcaça tinha correlação muito baixa com a quantidade de músculos na carcaça. Diferentemente do observado por Faulkner et al. (1990) e Bullock et al. (1991), não houve correlação significativa da AOL carcaça com a quantidade de tecido adiposo. Geralmente, as correlações envolvendo a $\mathrm{AOL}$ carcaça e aquelas relativas às medidas da $\mathrm{AOL}$ por ultra-sonografia são sempre no mesmo sentido (mesmo sinal), indicando que ambas medem essencialmente o mesmo parâmetro, entretanto, a magnitude destas correlações é sempre superior para a AOL carcaça, demonstrando a menor precisão da AOL ultra-som.

A ECG por ultra-sonografia (ECG ultra-som) mostrou correlações positivas com a porcentagem de tecido adiposo, com valores superiores ao encontrado por Bailey et al. (1986) e inferiores ao reportado por Faulkner et al. (1990), e a quantidade de tecido adiposo da carcaça, com valor inferior ao obtido por Bullock et al. (1991) e Faulkner et al. (1990). Também foram encontradas correlações negativas com as porcentagens de músculo e tecido ósseo, com valores inferiores ao observado por Faulkner et al. (1990), que também detectaram correlação significativa da ECG por ultra-sonografia e a quantidade de músculo na carcaça.

Foram encontradas correlações positivas da ECG da carcaça com a porcentagem e quantidade de tecido adiposo, conforme demonstrado por Faulkner et al. (1990), Bullock et 
al. (1991) e Peron et al. (1995). Também houve correlação negativa da ECG da carcaça e a porcentagem de tecido muscular, que, embora não tenha sido determinada neste estudo, muitos autores demonstraram que também pode ser positivamente correlacionada à AOL da carcaça (Faulkner et al., 1990; Arnold et al., 1991), ao peso da carcaça quente (Arnold et al., 1991) e às quantidades de músculo e de tecido ósseo (Peron et al., 1995). Como ocorre com a AOL, as medidas de ECG obtidas por ultra-sonografia e na carcaça se correlacionam no mesmo sentido com os parâmetros de composição da carcaça, mas, neste caso, a medida por ultra-sonografia apresenta as correlações de maior magnitude, talvez como conseqüência da maior variabilidade da medida tomada na carcaça.

A AOLPCAR se correlacionou positivamente com a porcentagem de músculo, como sugerido por Luchiari Filho (2000), porém com magnitude inferior à observada entre a AOL da carcaça e a porcentagem de músculo e negativamente com a porcentagem e a quantidade de tecido adiposo. A AOLUPKG, por sua vez, se correlacionou negativamente somente com as quantidades dos tecidos adiposo e ósseo, comprovando que a AOL obtida na carcaça possuiu maior correlação com a composição corporal que a obtida por ultra-sonografia. A quantidade de tecido adiposo demonstrou correlações de magnitude superior para AOLUPKG e AOLPCAR (Tabela 3).
O peso vivo, conforme constatado por Faulkner et al. (1990), teve grande influência nas características de produção (Tabela 3), observando-se correlações positivas com as quantidades dos cortes cárneos e dos tecidos muscular, adiposo e ósseo $(\mathrm{P}<0,05)$. O peso final também se correlacionou negativamente com a porcentagem de tecido ósseo, com valor inferior ao registrado por Faulkner et al. (1990). O peso da carcaça quente, assim como o observado por Faulkner et al. (1990), se correlacionou positivamente com as quantidades dos cortes cárneos e dos tecidos muscular, adiposo e ósseo e a porcentagem de tecido muscular, negativamente com a porcentagem de tecido ósseo $(\mathrm{P}<0,05)$.

Observaram-se correlações simples entre as características morfométricas da carcaça medidas por ultra-sonografia ou após o abate e alguns parâmetros da carcaça (Tabela 4). A AOL ultra-som se correlacionou positivamente com as quantidades de dianteiro e traseiro dos bovinos e a AOL carcaça, por sua vez, com as quantidades de dianteiro e traseiro e a porcentagem de traseiro $(\mathrm{P}<0,05)$.

A ECG por ultra-sonografia apresentou correlação positiva com a quantidade e negativa com a porcentagem de traseiro dos bovinos $(\mathrm{P}<0,05)$. Na ECG medida na carcaça, também foram observadas as mesmas correlações que a ECG por ultra-sonografia. A AOLPCAR mostrou correlação positiva com o rendimento de cortes cárneos e a porcen-

Tabela 3 - Correlações simples das variáveis com a composição corporal

Table 3 - Simple correlations between traits and body composition

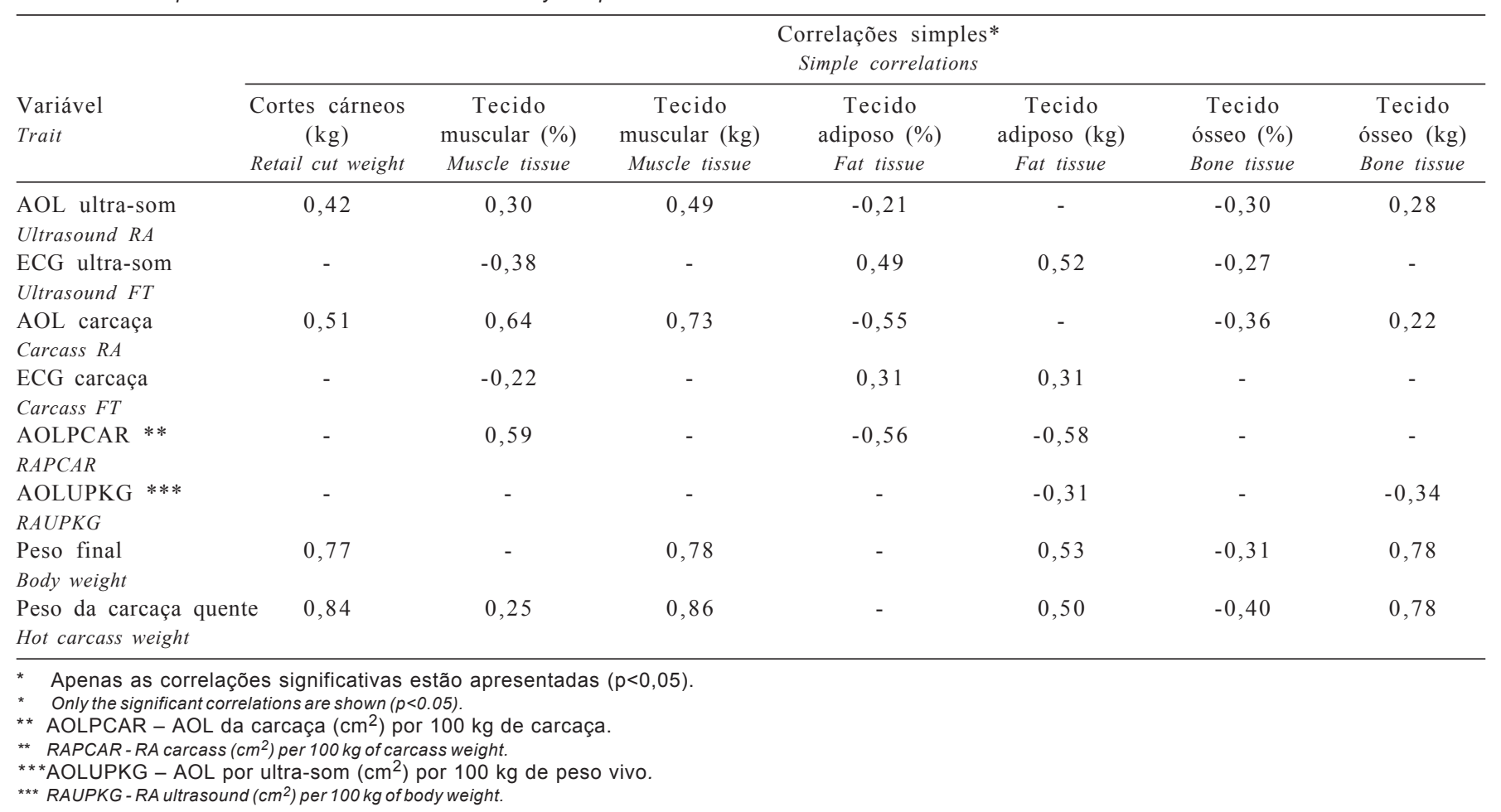


Tabela 4 - Correlações simples das variáveis com a composição da carcaça

Table 4 - Simple correlations of traits and carcass composition

\begin{tabular}{|c|c|c|c|c|}
\hline \multirow[b]{2}{*}{$\begin{array}{l}\text { Variável } \\
\text { Trait }\end{array}$} & \multirow[b]{2}{*}{$\begin{array}{c}\text { Rendimento de cortes cárneos (\%) } \\
\text { Retail cut yield }\end{array}$} & \multicolumn{2}{|c|}{$\begin{array}{c}\text { Correlações simples* } \\
\text { Simple correlations }\end{array}$} & \multirow[b]{2}{*}{$\begin{array}{c}\text { Traseiro }(\%) \\
\text { Hindquarter yield }\end{array}$} \\
\hline & & $\begin{array}{c}\text { Traseiro }(\mathrm{kg}) \\
\text { Hindquarter } \\
\text { weight }\end{array}$ & $\begin{array}{c}\text { Dianteiro }(\mathrm{kg}) \\
\text { Forequarter weight }\end{array}$ & \\
\hline AOL ultra-som (Ultrasound RA) & - & 0,43 & 0,43 & - \\
\hline ECG ultra-som (Ultrasound FT) & - & 0,36 & - & $-0,49$ \\
\hline AOL carcaça (Carcass $R A)$ & - & 0,33 & 0,38 & 0,31 \\
\hline AOLUPKG*** (RAUPKG) & - & - & $-0,28$ & - \\
\hline Peso final (Body weight) & $-0,45$ & 0,79 & 0,90 & - \\
\hline Peso carcaça quente (Hot carcass weight & $-0,44$ & 0,83 & 0,96 & - \\
\hline
\end{tabular}

* Apenas as correlações significativas estão apresentadas $(p<0,05)$.

* Only the significant correlations are shown $(p<0.05)$.

** AOLPCAR - AOL da carcaça $\left(\mathrm{cm}^{2}\right)$ por $100 \mathrm{~kg}$ de carcaça.

* RAPCAR-RA carcass $\left(\mathrm{cm}^{2}\right)$ per $100 \mathrm{~kg}$ of carcass weight.

***AOLUPKG - AOL por ultra-som $\left(\mathrm{cm}^{2}\right)$ por $100 \mathrm{~kg}$ de peso vivo.

*** RAUPKG - RA ultrasound $\left(\mathrm{cm}^{2}\right)$ per $100 \mathrm{~kg}$ of body weight.

tagem de traseiro $(\mathrm{P}<0,05)$, o que também foi relatado por Luchiari Filho (2000). A AOLUPKG apresentou correlação negativa com a quantidade de dianteiro $(\mathrm{P}<0,05)$. O peso vivo e o peso da carcaça quente se correlacionaram negativamente com o rendimento de cortes cárneos e positivamente com a quantidade de traseiro e dianteiro $(\mathrm{P}<0,05)$. Ao contrário do observado por Hamlin et al. (1995), May et al. (2000), que encontraram correlação significativa da ECG por ultra-sonografia com o rendimento de cortes cárneos, e Silva et al. (2001), que registraram correlação do rendimento de cortes cárneos com a AOL por ultra-sonografia, a AOL carcaça, a ECG por ultra-sonografia e a ECG carcaça, não se constatou neste trabalho correlação significativa entre o rendimento de cortes cárneos e as variáveis AOL e ECG por ultra-sonografia ou carcaça.

\section{Conclusões}

Os novilhos $1 / 2$ Simental Nelore e Canchim apresentaram alta deposição muscular e os Nelore, expressiva deposição de tecido adiposo. Os animais $1 / 2$ Angus Nelore se mostraram muito apropriados para o sistema de produção do novilho superprecoce, pois apresentaram equilíbrio entre musculosidade e gordura de acabamento.

A medida de AOL tem mesmo relação com a musculosidade da carcaça, porém, à medida que há incremento da AOL nos animais, pode ocorrer redução da ECG da carcaça, como resultado da correlação negativa entre a ECG e as porcentagens de traseiro e AOL.

Geralmente, as correlações envolvendo a AOL e a ECG por ultra-sonografia e aquelas relacionadas às medidas da AOL e ECG da carcaça são sempre no mesmo sentido, indicando que ambas medem essencialmente o mesmo parâmetro, o que valida a utilização da técnica da ultra-sonografia para predição das características da carcaça.

\section{Literatura Citada}

ARNOLD, J.W.; BERTRAND, J.K.; BENYSHEK, L.L. et al. Estimates of genetic parameters for live animal ultrasound, actual carcass data and growth traits in beef cattle. Journal of Animal Science, v.69, p.985-992, 1991.

BAILEY, C.; JENSEN, J.; BECH ANDERSEN, B. Ultrasonics scanning and body measurements for predicting composition and muscle distribution in young Holstein x Friesian bulls. Journal of Animal Science, v.63, p.1337-1346, 1986.

BERGEN, R.D.; McKINNON, J.J.; CHRISTENSEN, D.A. et al. Prediction of lean yield in yearling bulls using real-time ultrasound. Canadian Journal of Animal Science, v.76, p.305$311,1996$.

BERGEN, R.D.; McKINNON, J.J.; CHRISTENSEN, D.A. et al. Use of the real-time ultrasound to evaluate live animal carcass traits in young performance-tested beef bulls. Journal of Animal Science, v.73, p.2300-2307, 1997.

BULLOCK, K.D; BERTRAND, J.K.; BENYSHEK, L.L. et al. Comparison of real-time ultrasound and other live measures to carcass measures as predictors of beef cow energy stores. Journal of Animal Science, v.69, p.3908-3916, 1991.

CRUZ, G.M.; TULLIO, R.R.; ALENCAR, M.M. et al. Efeito do peso de abate sobre a qualidade de carcaça e o rendimento de cortes cárneos comerciais de bovinos jovens cruzados. In CONGRESSO BRASILEIRO DE CIÊNCIA E TECNOLOGIA DE CARNES, 1., São Pedro, 2001. Anais. Campinas: Instituto de Tecnologia de Alimentos, 2001. p.92-93.

DHUYVETTER, J. Beef cattle frame scores. Fargo: NDSU, 1995 $2 \mathrm{p}$.

FAULKNER, D.B.; PARRET, D.F.; McKEITH, F.K. et al. Prediction of fat cover and carcass composition from live and carcass measurements. Journal of Animal Science, v. 68, p.604-610, 1990 .

FROST, A.R.; SCHOFIELD, C.P.; BEAULAH, S.A. et al. A review of livestock and monitoring and the need for integrated systems. Computers and Electronics in Agriculture, v.17, p.139. $159,1997$.

GALVÃO, J.G.; FONTES, C.A.A.; PIRES, C.C. et al. Características e composição física da carcaça de bovinos não-castrados, 
abatidos em três estádios de maturidade (estudo II) de três grupos raciais. Revista Brasileira de Zootecnia, v.20, p.502-512, 1991.

HAMLIN, K.E.; GREEN, R.D.; CUNDIFF, L.V. et al. Real-time ultrasonic measurement of fat thickness and longissimus muscle diameter: II. Relationships between real-time ultrasound measures and carcass retail yield. Journal of Animal Science, v.73, p.1725-1734, 1995.

HANKINS, O.G.; HOWE, P.E. Estimation of the composition of beef cattle carcasses and cuts. Washington: USDA, 1946. (Technical Bulletin, 926)

HERRING, W.O.; MILLER, D.C.; BERTRAND, J.K. et al. Evaluation of machine, technician, and interpreter effects on ultrasonic measures of backfat and longissimus muscle area in beef cattle. Journal of Animal Science, v.72, p.22162226, 1994.

JOANDET, G.E.; CARTWRIGHT, T.C. Modeling beef production systems. Journal of Animal Science, v.41, p.1238-1246, 1975.

JORGE, A.M.; FONTES, C.A.A.; SOARES, J.E. et al. Características quantitativas da carcaça de bovinos e bubalinos, abatidos em diferentes estádios de maturidade. Revista Brasileira de Zootecnia, v.26, p.1039-1047, 1997.

LANNA, D.P.D. Estimativa da composição química do corpo vazio de tourinhos Nelore através da gravidade específica da carcaça e da composição de cortes das costelas. Piracicaba: Escola Superior de Agricultura Luiz de Queiroz, 1988. 131p. Dissertação (Mestrado em Ciência Animal e Pastagens) Escola Superior de Agricultura Luiz de Queiroz, 1988.
LUCHIARI FILHO, A. Pecuária da carne bovina. São Paulo: LinBife, 2000. 134p.

MAY, S.G.; MIES, W.L.; EDWARDS, J.W. et al. Using live estimates and ultrasound measurements to predict carcass cutability. Journal of Animal Science, v.78, p.1255-1261, 2000.

NATIONAL RESEARCH COUNCIL - NRC. Nutrient requirements of beef cattle. 7.ed. Washington, D.C.: National Academy Press, 1996. 242p.

PERON, A.J.; FONTES, C.A.A.F.; LANA, R.P et al. Medidas quantitativas e proporções de músculos, tecido adiposo e ossos da carcaça de novilhos de cinco grupos genéticos, submetidos à alimentação restrita e ad libitum. Revista Brasileira de Zootecnia, v.24, p.126-137, 1995.

STATISTICAL ANALYSES SYSTEM - SAS. SAS/STATTM guide for personal computers. 6.ed. Cary: 1987. 1028p.

SILVA, S.L.; LEME, P.R.; FIGUEIREDO, L.G.G. et al. Correlações entre características de carcaça obtidas in vivo por ultrasonografia e na carcaça post mortem em novilhos Nelore. In: REUNIÃO DA SOCIEDADE BRASILEIRA DE ZOOTECNIA, 38., Piracicaba, 2001. Anais... Piracicaba: Sociedade Brasileia de Zootecnia, 2001. p.1206-1208.

SILVEIRA, A.C. Sistema de produção de novilhos superprecoces. In: SIMPÓSIO GOIANO SOBRE PRODUÇÃO DE BOVINOS DE CORTE, 1., Goiânia. Anais... Goiânia: Colégio Brasileiro de Nutrição Animal, 1999. p.105-122. 